\title{
Explore for More: Enhancing Students' Literacy through a School-Family-University Partnership
}

\author{
Megan Parker Peters ${ }^{1 *}$, Jeanne Gilliam Fain ${ }^{2}$, Sarah Duncan ${ }^{1}$ \\ ${ }^{1}$ Associate Professor, Lipscomb University, Nashville, Tennessee, USA \\ ${ }^{2}$ Professor, Lipscomb University, Nashville, Tennessee, USA
}

Corresponding author: Megan Parker Peters, E-mail: mparkerpeters@lipscomb.edu

\begin{tabular}{l} 
ARTICLE INFO \\
\hline Article history \\
Received: May 03, 2018 \\
Accepted: June 28, 2018 \\
Published: July 31, 2018 \\
Volume: 6 Issue: 3
\end{tabular}

Conflicts of interest: None Funding: None

\begin{abstract}
Many educator preparation programs desire to partner with P-12 and community groups. The authors showcase the development of a P-12 School-University-Family partnership. Partnership goals included literacy growth and interest among linguistically and culturally diverse P-12 learners while also providing a sustainable training ground for current and future educators. Instead of decreasing students' literacy skills over the summer months, elementary students $(\mathrm{n}=40)$ experienced growth in both reading skills and enjoyment $(p<0.05)$ after participating in the discussed summer literacy program. Beyond student benefits, it should be remembered that both educator preparation programs (EPPs) and P-12 schools have much to offer each other and benefit reciprocally when they work together; methods for forming and sustaining a productive partnership are discussed. Recommendations for sustainability and future plans are discussed.
\end{abstract}

Key words: Partnerships, Educator Preparation Programs, Teacher Education, Literacy Education

\section{INTRODUCATION}

It is no longer novel to realize that educator preparation providers (EPPs) are training candidates to support and mentor diverse P-12 classrooms. America's P-12 classrooms continue to evolve and include students from a wide array of families, nationalities, languages, and background experiences. For example, in Nashville, a southern, land-locked city, 30\% of students reside in households in which English is not the primary language (Jacobs \& Hearne, 2016). Accordingly, more than 140 different languages are spoken in Nashville households (Garrison, 2014). The most rapid increase has occurred among Latinos, a group of students was once a true minority but now accounts for more than $20 \%$ of Nashville, Tennessee's, student population (Garrison 2014; Jacobs \& Hearne, 2016). It is essential that there is a connection between teacher training and the unique needs of a community.

This is a critical moment. Teacher education candidates must be considering the diverse perspectives of the families in their future schools. With the advent of more students and families who speak and read languages other than English, there must be efforts from teacher preparation programs to support current educators, families, and future teachers who will instruct and mentor children of the community (Scott $\&$ Scott, 2015). It can no longer be an expectation that P-12 students can take an English-language textbook home and receive substantive parental assistance. Educator preparation programs have a responsibility to notice and respond to the community's needs. Families' home-languages and cultures must be considered; P-12 student success depends on it. Candidates cannot simply read and talk about issues of diversity. Teacher Education candidates must be equipped to support the success of a diverse community of students, and educator preparation providers must pave the way by connecting candidates, schools, P-12 students, and families.

In this article, we seek to showcase how a P-12 School-University-Family partnership can fuel literacy growth and interest among linguistically and culturally diverse learners while also providing a sustainable training ground for current and future educators. The researchers employed a summer literacy camp as a means to increase literacy proficiency and enjoyment among multi-lingual students at an economically disadvantaged school. We also seek to share how we constructively created strategic and intentional space for P-12 students and families to learn about literature and reading by design for early linguistically and culturally diverse learners. Both educator preparation programs (EPPs) and P-12 schools have so much to offer each other; in this article, we will also share our methods for forming a productive partnership.

\section{LITERATURE REVIEW}

\section{Student Home Life and Resources}

The population of P-12 students in American schools is changing, and these changes have undoubtedly contributed to the performance patterns of our students. Suitts (2015) notes statistics from national sources such as The Washington Post, NPR, and The New York Times showcasing that the majority (51\%) of America's P-12 public school student 
population reside with poor families. We can no longer assume that American students enjoy academically-enriched summers of museum trips, cultural events, and geographic travel. The resources are not available. Long gone are the days of stay-at-home-moms taking school-age children to activities and enrichment all summer. A 2016 Washington Post article notes that approximately two-thirds of families are led by single parents or two working parents (Paquette, 2016). Instead of assuming that students will continue active learning during the summer months, educators instead have to consider less traditional, more resource conscious options to support academic maintenance and retention of learning.

\section{Academic Impacts of Summer}

However, students love summer. Instead of being told what to do, there are choices. Students can choose when they wake, who they will see, and what they will do. During the academic year, students follow a routine of studying a wide array of topics and read each day. But, for many, this pattern is forsaken during the summer months. Thus, it is of no surprise that "summer slide" has become a part of the educator's vocabulary. Summer slide is the idea that students' academic progress slides backwards during the summer months. Because students are not practicing academic skills on a regular basis during the summer, they lose some familiarity and fluency of skills that were mastered and practiced during the school year (McGill-Franze, Ward, \& Cahill, 2016).

The decline in reading achievement over the summer is well-documented and has been shown to particularly affect economically disadvantaged students and families (Alexander, Entwhistle, \& Olsen, 2007; Allington \& McGill-Franzen, 2003; Wilkins et al., 2012); due to lack of resources, these families are not able to supplement the summer days of freedom with many of the enriching summer experiences afforded to students residing in wealthier households. In 2011, McCombs and colleagues found that elementary students lost about a month's worth of academic growth during the summer months; and, lower-income students experienced the greatest drop. McGill-Franzen and Allington (2001) note a summer loss of 3 months, which accumulates to 18 months by the time a student reaches sixth grade. Johnson reported a similar trend in a 2000 US Department of Education report, documenting that the achievement gap between children who reside in high and low SES families increases through the elementary years, fueled by summer losses that widen the gap each year. Smith (2012) also noted that "summer learning loss is cumulative" and that the continued drops in achievement experienced by lower-income students contributes to these students' future performance and lack of desired progress. Alexander, Entwisle, and Olson (2007) examined students' progress and retention of information longitudinally, from $1^{\text {st }}$ grade to age 22 . On a positive note, low-income students made equivalent progress in reading during the academic year compared to higher-income children. However, the the difference-maker came in the summer; the reading skills of students in lower-income families decreased during the summer months. Looking at the long-term data, Alexander and his colleagues concluded that over half of the existing $9^{\text {th }}$ grade reading achievement gap can be attributed to "unequal access to summer learning opportunities during elementary school" (Smith, 2012, p. 60). Though many schools and districts have made strides in bringing literacy to the forefront, it seems that the yearly three months of academic freedom may be detracting from the nine months of consistent academic focus.

\section{Summer Reading Programs}

Summer reading programs are not uncommon to American students. In libraries across the country, summer reading programs are offered to students. Students often submit their summer reading logs in exchange for covetable, motivating prizes. Heyns' (1978) classic study set the bar for better understanding the learning that can stem from summer reading programs. She followed sixth and seventh grade public school students for two school years, including the summer between the school years. She found that the number of books read during the summer is consistently related to academic gains. And, children in every income group who read at least six books during the summer gained more in reading achievement than children who did not read at least six books. Perhaps, one of the most powerful findings was that participation in public library reading programs during the summer was more predictive of future vocabulary gains than participating in summer school through the child's home school. Heyns found that the main factors determining whether a child read over that summer included the child's use of the public library; the child's sex (girls read more than boys); the child's family's socioeconomic status; and the distance from the child's home to a library. She concluded:

More than any other public institution, including the schools, the public library contributed to the intellectual growth of children during the summer. Moreover, unlike summer school programs, the library was used by over half the sample and attracted children from diverse backgrounds. (Heyns, 1978, p. 77)

On a large scale, library-based summer reading programs were studied by Roman and Fiore (2010). They conducted a 3-year study among 357 rising fourth-grade students who qualified to receive free/reduced lunch. Participating public libraries and students were required to engage in a library-based summer reading program that was at least 6 weeks long in duration. Pre- and post- literacy inventories were administered to participating students. Participating students also completed reading logs during the summer months in addition to completing surveys, which were also completed by parents, teachers, and librarians. They found that there is merit in the library-based programs; the students who participated in the public library summer reading programs did not experience summer loss in reading as measured by the post tests administered in their schools. Students who were a part of a consistent reading program during the summer continued to practice literacy skills that were developed over the school year. Instead of waiting three months to practice skills learned in May, students who participated in library-based summer reading programs regularly practiced these skills and maintained instead of losing literacy skills.

Wilkins and colleagues also examined a number of summer reading programs in 2012 . They found that most sum- 
mer reading programs met the goal of sustaining or improving student reading levels over the summer months away from school. The researchers also note that providing students with books, even without a formal program, supported reading growth.

\section{Pre-service Teachers' Training Needs}

Theory and practice are essential to successful teacher education (Grossman, Hammerness, \& McDonald, 2009; Korthagen, Kessels, Koster, Lagerwerf, \& Wubbels, 2001). One cannot expect candidates to successfully support their future students without practical experience as a part of their teacher preparation program. In the same vein, engaging in practice without supporting research can also be futile. There should be a blended overlap; both should influence and complement each other as candidates are prepared for the classroom. With the evolving student population in schools, Education Preparation Providers (EPPs) must also be intentional with clinical and theoretical preparation. Teacher education candidates should learn about culturally-responsive teaching methods and should participate in clinical placements that allow them to work with learners representative of both the local community and the nation's P-12 educational community at large. Candidates should understand the changing definition of family (Paquette, 2016) and how family dynamics impact the educational team.

Partnerships between university EPPs and P-12 schools are an obvious vehicle for combining theory and practice in an authentic way. Partnerships allow EPPs to provide opportunities for candidates to apply theory, reflect on their decisions, and have more opportunities to try other options and improve over time in a real learning environment (Darling-Hammond, 2006; Jones et al., 2016). The program Camp Explore was born out of the dual needs to provide adequate training for our candidates and to support the literacy needs of the children in our community, especially as they enter the unschooled season of summer.

\section{Research Questions}

Specifically, we crafted the following research questions:

1. Will students' reading levels be maintained over the course of the summer upon completing a literacy-focused summer camp?

2. Will students' attitudes about reading become more favorable upon completing a literacy-focused summer camp?

3. Will students' families perceive the literacy-focused summer camp as a valuable experience for their children?

\section{THE CURRENT STUDY}

Camp Explore began as a partnership with Jem Elementary, an urban, Title I school, in the southeastern United States. "Jem" Elementary and all following names are pseudonyms for the actual participants. Jem Elementary is an ethnically, linguistically, and culturally diverse school that features a population that is considered "struggling" due to performance data on standardized testing. Jem Elementary serves 888 students. Of those, $94.4 \%$ are economically disadvantaged, and $54.3 \%$ are English Learners.

The EPP-P-12 partnership developed as the second author initially involved graduate students and collaborated with Jem Elementary to plan a family literacy night at the school. Here, graduate students were able to practice strategies that they had been learning in their coursework, and Jem students and families were able to engage in a literacy experience matched to their cultural and linguistic backgrounds. Family literacy night was an overwhelming success with more than 400 attendees. The only identifiable weakness of the family literacy night was the fact that families could not take the books home. This weakness led to the next step of the greater plan.

Seeing that Jem Elementary's families wanted books, the second author pursued a grant that would allow her to purchase and provide books matched to the cultural and linguistic makeup of Jem Elementary. Again, this was an opportunity for the EPP to collaborate and partner with a local P-12 school and its families. A grant was awarded, and the EPP researchers worked with Jem teachers to ensure that the books provided to the school's students reflected the cultural and linguistic heritage of the students in addition to being high quality pieces of literature. This was an opportunity for candidates to engage in authentic learning; candidates were able to observe and assist in book selection, considering factors of language, culture, developmental appropriateness, and interest all while benefitting P-12 students who were provided access to quality literature.

Based on these smaller experiences, it was evident that the EPP and Jem these smaller experiences worked to lay a strong foundation with both partners experiencing mutual benefits. Both parties had had successful experiences with each other. In addition to the smaller joint ventures, the EPP has a longstanding, working relationship with local school system. When the opportunity arose to engage in a longer, more comprehensive literacy program that would potentially offer greater benefits to students, families, and the EPP, it was a natural next step forward in the partnership. Camp Explore was ready to grow from the seeds that had been planted over many months. The EPP anticipated that, as a result of the successful implementation of Camp Explore, the EPP and school system could work together to replicate this model in other Title I multilingual schools, furthering the partnership. The camp's framework has the potential to boost literacy achievement for many students while also providing essential experiences for EPP candidates.

\section{METHODS}

\section{Participants}

Camp Explore at Jem Elementary was one of 12 camps to be awarded a grant to provide a rich literacy learning experience for 40 rising first through third grade students. Camp Explore was born. The authors worked with the local school system to identify Jem Elementary as an urban, Title I ele- 
mentary school that included a student population that could benefit from extra summer reading intervention. Jem was also a preferable setting for Camp Explore as it is an ethnically, linguistically, and culturally diverse school, providing a valuable clinical experience for candidates who would be involved in Camp Explore. Jem Elementary's student body contains 54.3\% English Learners and 94.4\% economically disadvantaged students among its total 888 students.

Forty first through third grade students from Jem Elementary participated in Camp Explore. Convenience sampling was employed; Jem Elementary was selected to participate in the summer literacy grant experience based upon its students' current literacy levels. The 40 participants included 21 males and 19 females. Fourteen first grade students, 12 second grade students, and 14 third grade students from Jem Elementary School participated in Camp Explore. Consent forms were sent to families upon registering for Camp Explore. Four languages were represented in the 40 student participants: English, Arabic, Kurdish, and Spanish. All participants qualified for free or reduced lunch, representing low-SES families.

Camp instructors were selected from current Jem Elementary teachers and current and former teacher candidates from the partnering EPP. All participating instructors received six hours of professional development on integrating multicultural texts and balanced literacy. Jem teachers were sought out due to their relationships with the students, parents, and the community. The EPP's prior involvement at the school paved the way for recruiting, and the working relationships established between partners helped in selecting teachers who would be a good fit for the program. Graduate students from the EPP were targeted and selected for teaching positions because they were all strategically taught to know and execute the balanced literacy framework that the camp employed. Additionally, the graduate students and their teaching skills were well-known to the camp directors (second and third authors).

In addition, the EPP currently has a program to recruit diverse teacher candidates; the EPP visits local high schools and identifies students with diverse backgrounds who are interested in teaching. Mentoring and scholarships are offered to qualified candidates. The program director of our recruiting initiative reached out to several candidates who were set to attend the EPP the following semester as freshmen and some high school juniors who expressed an interest in teaching and our program. These students were invited to apply to work as interns at the camp and support teachers and students during the program. This brought more teacher-leaders of diversity to the classroom and allowed students to see and identify with teacher-leaders who looked more like them (Dee, 2004; 2005; Zirkel, 2002).

\section{Framework and Curriculum}

Based on research regarding successful University-School partnerships (Jones et al., 2016), the research team knew that it was essential for our program and research design to have guiding frameworks. Rosenblatt's (1978) transactional theory provided a guiding framework for the design of
Camp Explore. Rosenblatt's theory reflects the appreciation of diversity, reminding us that readers come to every text with personalized experiences, circumstances, and abilities (Probst, 2002; Rosenblatt, 1978). In addition, Vygotsky's (1978) sociocultural theories of learning and literacy catalyzed building intentional spaces for making critical connections with texts (Vasquez, Tate, \& Harste, 2013). As such, all camp classrooms were equipped with classroom libraries that offered students access to globally-representative texts for children. Finally, Camp Explore also used a balanced literacy model, which is recommended for all students, including struggling readers and English learners (Braunger \& Lewis, 2006). A key component of this included guided reading using texts at students' instructional level to develop independence (Calkins 2001; Fountas \& Pinnell, 1996). Beyond the P-12: EPP partnership, family learning partnerships were also established. Camp Explore sent home dual-language books written in English and children's home languages in order to support family book reading.

To guide the research component of Camp Explore, we leaned on ideas from developmental psychologists, Bronfenbrenner and Vygotosky, in addition to foundational research on the development of reading enjoyment. Bronfenbrenner (1992) presented the idea of systems of influence on development. A child has many layers of environmental influence, including family, school, opportunities, and culture. In our research model and program design, we were aware that a diverse group of students from diverse environments would be participating. We knew that students would come to us with various environmental influences supporting or discouraging a love of reading. Cultural values and differences in opportunity could also impact baseline reading preferences and skills. In addition, Vygotsky (1978) had an impact on the research framework; students were assessed with a running records literacy assessment at the start of Camp Explore. Their demonstrated reading skill level provided information to support student learning within their zone of proximal development. Students' baseline reading level was used to drive decisions and appropriate scaffolding supports for student literacy choices. However, we hoped that literacy skills would be improved over the summer due to greater opportunities for rich literacy experiences that would also be paired with an increased enjoyment of reading. Nell (1988) wrote about the psychology of reading for pleasure. Nell's theories and long-term studies support the notion that as reading skills increase, individuals report stronger reading enjoyment. With opportunities to read greater quantities of material, read material at or just above a student's level of skill, and share these experiences with family, students summer Camp Explore experience is influenced by these seminal ideas, which we hoped would catalyze improved reading skills and a greater love of reading.

\section{Measures}

The researchers intentionally inserted opportunities for data collection. Camp Explore included the collection of quantitative data (running records, motivation surveys, and family backpack surveys) to explore the major research 
questions. Thirty-eight of the 40 participating students completed pre-post motivation surveys and reading assessments. For reading assessments, students completed running records exercises with the researchers at the start and end of Camp Explore. Marie Clay (1993, 2000, 2001, 2006) developed running records to deeply analyze a student's reading, make diagnosis, and create a plan for improvement for the reader. Fountas and Pinell (2008) indicate running records allow teachers to observe what readers are doing as they read and process texts. The observations help teachers to infer what readers are doing as they problem solve while they are making meaning from the text. The researchers used students' end-of-year reading level as documented by Jem records to determine an appropriate reading level for running records. Students' pre- and post- camp reading levels were documented in addition to their percent correct during the running records pre- and post- exercises.

Students completed McKenna and Kear's (1990) Elementary Reading Attitude Survey as pre and post reading motivation surveys in order to gauge attitudes and changes in attitudes about reading. Here, students responded to 20 pictoral ("Garfield") Likert-scale items, such as "I enjoy reading a book during free time" and I "enjoy reading out loud in class." The McKenna and Kear (1990) measure is well-known in the field and was normed with a population of 18, 138 first through sixth grade students in American schools. Cronbach's alpha was calculated at each grade level with coefficients ranging from 0.74 to 0.89 . Construct validity was calculated in several ways. First, participants were divided into two groups based on library card ownership; those with library cards reported significantly higher recreational reading scores. Construct validity was also indicated by comparing participants who currently had library books versus those who did not. Again, those who had books check out at the time of the survey reported higher scores than those who did not. As a final demonstration of construct validity, participants were divided by television viewing. They were grouped by those who watch less than one hour of television per day versus those who watch more than two hours each day. Recreational reading was higher among participants who viewed less than one hour of television each day.

Students' families also completed a parallel reading interest and satisfaction survey at the end of the summer program
(Appendix A). It was a Likert-based survey in which participants rated items from strongly disagree (1) to strongly agree (5). Family backpack surveys were created by the researchers and included six rating scale items. Surveys were translated to the languages spoken by participating families (e.g. Arabic, Kurdish, Spanish). The Family Survey included items similar to that of the McKenna and Kear scale; however, this measure was to be completed by participants' families and indicated families'value for reading and books for their children. The survey items assessed value of the provided books and according Camp Explore experiences. Some of the item prompts include: "I enjoy reading the family backpack books;" and "I believe that the books are helping my child as a reader." Cronbach's alpha was computed for internal consistency of items (0.71). Content validity was established through expert review using Lawshe's method (1975). Faculty with expertise in literacy and family studies reviewed potential survey items for content and determined which items contained content that was considered essential, useful but not essential, or not necessary. Only items that were deemed essential unanimously by the expert panel were included in the final version of the survey.

\section{Procedures}

A team of faculty members from the EPP was involved in drafting the grant proposal and collaborating on curriculum development for the camp's reading and writing units. The process of designing and working at the camp led to meaningful professional development and learning for the faculty involved. Upon notification of receiving the summer literacy grant, the researchers began designing the summer literacy camp (Figure 1).

The process also facilitated new relationships across campus for the goal of providing a high-quality camp. Faculty in the EPP reached out to colleagues in the College of Arts and Sciences for support in planning cross-curricular units (e.g. sciences). The university library was asked to purchase the core collection of diverse books to be used in camp, and they were able to supply over 40 titles to the camp that were incorporated into the university library's collection after camp was complete. Those titles are now frequently used by EPP faculty and candidates. Camp Explore also addressed a
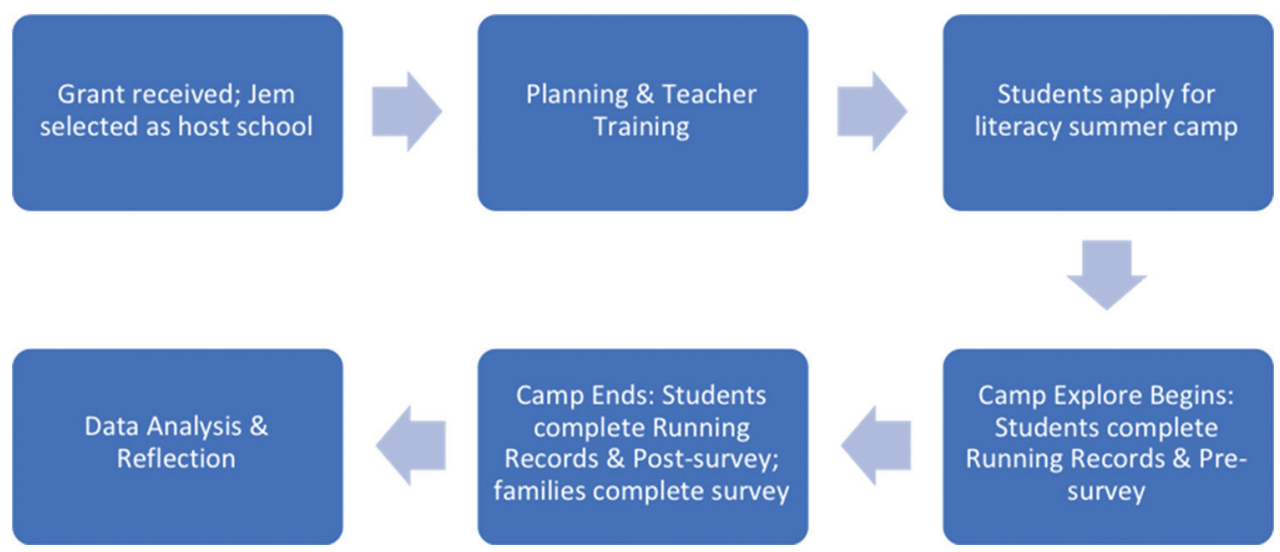

Figure 1. Procedures 
continual challenge for the EPP each summer-candidates accessing high-quality field experiences in a diverse setting. The camp offered an ideal opportunity for candidates to observe the literacy practices and ELL strategies they were studying about in their courses "in action" as they were being taught to diverse learners. Candidates were also able to teach or co-teach lessons in a highly supportive environment that allowed for creative instruction. Interns from our diverse teacher recruitment initiative gained experience in a school setting before even beginning our program. They were also able to build relationships with faculty members by working alongside them during the summer.

Thus, leaning on theory to guide our practice, Camp Explore aimed to create a research-based model and partnership that focused on developing and improving literacy skills and motivation in elementary-age culturally diverse readers and readers with emerging proficiency as demonstrated by literacy data. We sought to equip current elementary teachers and our current graduate students in the effective use of research-based literacy strategies all teachers and graduate students were provided with targeted professional development prior to the start of Camp Explore. Teacher professional development was provided by professors from the EPP and held at the school site. Before Camp Explore began, teachers were given six hours of professional development on the balanced literacy framework used in the camp and an introduction to the global, informational, and multicultural texts used in the camp. They were also provided with three professional books on teaching reading and writing. The literature selections that were used in the camp were current titles released in the last two years. Books considered were analyzed based upon multiple information sources and reviews for book selection including the Worlds of Words organization, International Board on Books for Young People, United States Board on Books for Young People, Orbis Pictus (nonfiction award), Caldecott Award, Newbery Award, Pura Belpre Award, Coretta Scott King Award, Horn Book, American Library Association, Language Arts, Amazon, and Parnassus Bookstore. Teachers commented that they "really enjoyed the opportunity to learn about so many new, high quality books" - something they rarely have time to research on their own during the busy school year. Additionally, camp instructors participated in a co-teaching model with faculty members from the EPP. Faculty members taught alongside instructors and interns, modeling strategies and mini-lessons and providing daily opportunities for candidates to view research-based literacy instruction.

Camp Explore class sizes were kept small with a teacher to student ratio of 1:5; most classrooms consisted of 10 students taught by two teachers. The small classes, along with instructional support and a reprieve from pacing guides, standardized tests, and other pressures, created a teaching environment very different from the typical classroom during the regular school year. Teachers were able to improve their practice by observing new strategies and trying them out in a low-stakes, supportive environment. While this professional development emphasized the research-based strategies that would be employed during Camp Explore, it was hoped that these strategies and texts would be used in school-year classrooms for years to come.

The researchers worked closely with Jem families and administration as the logistics and programming planning were completed. The researchers drew upon sociocultural theories of learning and literacy (Vygotsky, 1978) and critical literacy research, which informed the research and camp design. The researchres wanted to create intentional spaces for students' book selection of critical connections with texts (Vasquez et al., 2013). All camp classrooms were equipped with classroom libraries designed to offer a good balance of what Bishop (1990) describes as "windows and mirrors"- some books were chosen because they reflected students' cultures, while others gave students a peek into global perspectives, rich informational text, and social justice issues. Texts were shared daily during interactive read-alouds to provide authentic literacy experiences, encourage critical discussion, and provide opportunities for reflective and creative writing. Students also had frequent opportunities to select texts of their choosing from the wide range of books, which increases reading motivation and autonomy (Gambrell, 1996, 2011; Spaulding, 1992). Camp Explore utilized a balanced literacy model, which is recommended for all students, including struggling readers and English learners (Braunger \& Lewis, 2006). A key component of this included guided reading using texts at students' instructional level to develop independence (Calkins 2001; Fountas \& Pinnell, 1996). In addition, candidates were afforded authentic opportunities to observe and practice the balanced literacy model in an authentic medium. Further, explicit strategy reading instruction (Serravallo, 2015) was integrated and supported throughout guided reading and interactive read-alouds.

Combining these elements, Camp Explore was a 4-week summer day camp with a literacy focus. Before Camp Explore began, students completed the Pre- Motivation and Interest Inventory. The researchers also collected reading level data from Jem and completed running records with each student participant on the first day of Camp Explore. Participating students were involved in reading and writing each day of the program. Their reading and writing were supported by experiences and choice. Each week of the 4-week camp, students were afforded opportunities to go to the local library (where each student and family registered for a local library lending card) in addition to enrichment field trips that connected to the literature choices provided to students each week. For example, students visited a zoo and visual arts center as two of their field trips. They were also afforded opportunities of choice; camp faculty intentionally selected books for the camp lending library based on the cultural backgrounds, languages, and enrichment activities experiences by the student participants. Students completed journaling activities connecting their experiences to what they were reading. Students also left Camp Explore with new books to keep for a growing home library. At the end of the 4-week camp, students were again assessed with running records, and their reading level was established. Students were also re-administered the Reading Interest and Motivation scale again as a post measure. 
Beyond the P-12: EPP partnership, family learning partnerships were established. Camp Explore sent home dual-language books written in English and children's home languages in order to encourage family book reading. The development of children's home language supports English learning (Wiley \& DeKlerk, 2010), and reading books at home in the child's primary language can support learning of vocabulary and concepts when the books are later read aloud in English at school (Roberts, 2008). Families were provided with eight books, including global and informational texts that were carefully selected to reflect students' cultures and provide opportunities for family discussion and sharing. Families also completed a post-survey at the end of Camp Explore, noting their value for reading and the Camp Explore program.

The authors collected and organized pre, post, and family performance and survey from participating students and families after Camp Explore ended. Data were organized and analyzed using the Microsoft Excel Statistical Package. Descriptive statistics and t-tests were employed to analyze the current data set.

\section{RESULTS}

Though Camp Explore was only a few weeks in length, some significant results were found. Microsoft Excel Statistical Package was used data organization and analysis. Prior to the main analyses, the distribution of participation data was checked for normality. The ratios of skewness and kurtosis for all the total values of pre/post survey items were within \pm 1.5 , indicating an assumption of normality of the data distribution. At the start of the summer program, students' running records, as assessed by individual student running records, were calculated as a mean score of $88.3(\mathrm{~N}=40)$. This means that student participants were reading at their end-of-school-year reading level with $88.3 \%$ mastery. At the end of Camp Explore, the students' mean running records score was $94.7(\mathrm{~N}=40$; Table 1$)$.

A paired samples t-test was employed to assess for differences in running records proficiency before and after Camp Explore. The students' mean proficiency growth from $88.3 \%$ (pre-test) to $94.7 \%$ (post-test) was significant at the $\mathrm{p}<0.05$ level (Table 2).

Table 1. Distribution of scores

\begin{tabular}{lcc}
\hline & M (SD) & n \\
\hline Running records & $88.3(4.88)$ \\
$\quad$ Pre-test & $94.7(2.73)$ \\
$\quad$ Post-test & \\
Reading inventory (Pre-test, selected items) & $2.3(1.1)$ \\
How do you feel about spending free time reading a book? & $3.11(.72)$ \\
How do you feel when you read out loud during class? & $2.52(1.01)$ \\
Reading Inventory (Post-test, selected items) & $3.12(1.03$ \\
How do you feel about spending free time reading a book? & 40 \\
How do you feel when you read out loud during class? & $4.32(0.62)$ \\
Family survey & $4.44(0.57)$ \\
I read the family backpack books regularly. & $4.6(0.57)$ \\
I enjoy reading the family backpack books. & $4.8(0.62)$ \\
I believe that the books are helping my child as a reader. & $4.87(0.36)$ \\
I see my child talking about the books and making connections with the books. & $4.4(0.69)$ \\
I think the family backpack books encourage my child to read. & 40 \\
I need more books to read in my home. &
\end{tabular}

Table 2. Paired samples t-tests (pre/post) $(n=40)$

\begin{tabular}{|c|c|c|c|c|}
\hline Test & M (SD) & df & $\mathbf{t}$ & $\mathbf{p}$ \\
\hline \multicolumn{5}{|c|}{ Running records } \\
\hline Pre & $88.3(4.88)$ & 39 & -9.44 & 0.02 \\
\hline Post & $94.7(2.73)$ & & & \\
\hline \multicolumn{5}{|c|}{ Reading survey: How do you feel about spending free time reading a book? } \\
\hline Pre & $2.3(1.1)$ & 39 & -2.12 & 0.02 \\
\hline Post & $3.11(0.72)$ & & & \\
\hline \multicolumn{5}{|c|}{ Reading survey: How do you feel when you read out loud during class? } \\
\hline Pre & $2.52(1.01)$ & 39 & -2.45 & 0.03 \\
\hline Post & $3.12(1.03)$ & & & \\
\hline
\end{tabular}


Most students' (32; 81\%) reading level also increased over the course of the summer. The majority of Camp Explore participants started at one reading level (e.g. K) and ended the summer reading with proficiency at a higher level (e.g. M). Reading levels were converted to numbers (e.g. A $=1, \mathrm{~B}=2$ ). Then, students' baseline reading level at the beginning of the summer was averaged, creating a pre-camp reading level for the group. At the end of Camp Explore, students' reading levels were again converted to numerals and averaged. As a total group, students' mean pre and post reading levels were compared with a paired samples t-test to test for significance between pre and post Camp reading level; the students' growth was statistically significant ( $\mathrm{p}<$ $0.05)$. Due to the small sample size $(\mathrm{N}=40)$, all grades (first through third) were combined in the data analyses. Many P-12 students are losing academic and specifically literacy proficiency over the summer months, but Camp Explore students actually grew stronger.

Students also completed pre and post reading motivation surveys in order to gauge their attitudes towards reading. McKenna and Kear's (1990) Elementary Reading Attitude Survey was employed with permission. Students' mean scores on the reading motivation surveys were compared pre and post Camp Explore. We found that students' attitudes toward reading changed positively by the end of the program, as reported by significant gains in mean scores on two specific items. Students' pre and post-Camp reading motivation scores were averaged by item. Then, pre and post mean scores were compared by item with paired t-tests to analyze potential significance. Students were significantly more likely to agree that they "enjoyed reading a book during free time" $(p=0.02)$ and that they "enjoyed reading out loud in class" ( $p=0.03)$ at the end of Camp Explore; as students' proficiency with reading rose as indicated by running records and rising reading levels, so did their confidence and enjoyment, as indicated on the reading motivation scale.

Family members also completed reading interest and satisfaction surveys at the end of the program. The survey was written in families' home language. It was a Likert-based survey in which participants rated items from strongly disagree to strongly agree. Family members from 27 of our 40 student participants completed the reading satisfaction surveys. For each of the six items, the mean score among the 27 completers was at least 4.32 (out of 5); a score of "4" indicates that the family member agreed with that statement. The highest score was "5," indicating "strongly agree." Some of the strongest agreement items on this survey include: "I enjoy reading the family backpack books" $(M=4.44)$; "I believe that the books are helping my child as a reader" ( $M=$ 4.6); and "I think the family backpack books encourage my child to read" $(M=4.8)$.

\section{DISCUSSION}

Based on our small-scale action research data, our research questions can be positively answered. Students who participated in Camp Explore increased their mean reading levels. In addition to increased reading levels, participating students increased their proficiency with running records. Over the course of the summer, a group of students from low SES homes increased their reading levels and proficiency; this opposes the summer slide research, which indicates that students often lose academic ground over the summer. But, even with these exciting data, we do not know the longevity of the data. What happens to these students next summer? Will the gains remain? What supports and opportunities are needed to realize continued literacy growth for students? A long-term plan for supporting students' literacy skills across the district should be discussed and organized. One year of success with a group of students is inspiring, but there must be long-term plans to support sustained mastery for these and other students across a district. A possible recommendation could include finding targeted areas to create an elementary and middle school camp. In addition, adding a career readiness intership for ningth and tenth graders. This plan would be longitudinal and strategic. It could show sustainable gains over time in high need areas.

With this growth in reading skills, students also reported higher levels of reading enjoyment. Self-efficacy may be growing. As students realize that they are capable readers, that they are capable of reading and experiencing success, they may also internalize that reading is enjoyable. They are not failures; this is not another opportunity to be recognized for errors. Students may now internalize, "I am a reader. I can do this well." With the level of autonomy and choice provided to students at Camp Explore, they may also be reaping the benefits of Deci and Ryan's self-determination theory. Students were provided choices of reading materials, rather than being directed to a prescribed text. They could find books that included topics of interest that were also matched to their language; this crystallizing combination may not have been actualized prior to Camp Explore but could have provided a ripe opportunity for a love of reading to catalyze.

In addition, students' families appeared to recognize the value of Camp Explore. Their positive responses on the post-camp survey indicated that reading is valued. Literacy is valued enough to support an academic summer camp for their children. Instead of leaving students at home during the 4-weeks of summer, families chose to support their students by sending them to Camp Explore. Families valued the opportunities for literacy exposure and growth during the summertime. Perhaps, this can inspire future funding or opportunities for family and community literacy engagement to support literacy growth and enjoyment for readers of all ages.

\section{CONCLUSUION}

\section{Lessons Learned}

In addition to the clear benefits to all partners, including P-12 literacy growth, teacher training, and candidate experience, there were important lessons learned while facilitating Camp Explore. First, it is paramount to have a buy-in from all involved; this includes the EPP and P-12 faculty but also P-12 leadership, especially the school principal. The P-12 principal is a critical member of the team as the principal can 
provide connections, support, and knowledge of the families and culture that exist within the school. This is important context for faculty who are planning a partnership program and teacher candidates who are learning about the contextual impacts of school culture. It is also important for everyone involved to have defined roles and understand their responsibilities. Everyone involved with a partnership should consider individual roles and best fit. This includes parents and guardians; support from P-12 parent organizations can be an asset to the partnership. Parent involvement indicates greater value and commitment to the program, which benefits P-12 students. Also, as the camp period comes to an end, it is important to consider sustainability; how can the benefits continue after camp ends? Are there local groups that may be interested in sponsorships? Does the PTO have an interest in summer literacy programs? Is there a way to provide teacher candidate practicum hours to candidates who teach or assist with the program? Family book clubs during the school year with students and families would also allow for continued focus on literacy beyond summer.

\section{Advice for EPPs: Starting a University-School-Family Partnership}

Schools and EPPs often want to form partnerships --and realize the value of partnerships-- but do not always know how to create a mutually-beneficial connection. EPPs should make efforts to connect with local P-12 school administrators; both parties are often looking for partnership opportunities and have mutual needs. It is important for partners to think about ideas that consider the voices of students, families, community, students, teachers, and teacher educators. Once needs are identified, EPPs and districts should explore the possibilities that will address the identified needs. In this case, both parties were interested in literacy. Jem needed more literacy instruction and exposure for its students. The EPP sought opportunities for candidates to use literacy pedagogy skills. The partnerhip in the form of Camp Explore allowed both needs to be met, and the partnership opportunity was a ripe opportunity for data collection to demonstrate the effectiveness, positive change, and value of summer literacy programs. It may be wise to start with a small partnership project, such as a one-time literacy night, involving teacher candidates, families, and students. This could be a smart way to gauge interest and feasibility of a larger partnership project. In addition, it is wise to look for grants to support the partnership work.

\section{Limitations}

It is acknowledged that this is a small-scale study, and the participants represent a group that could not generalize to many populations. Only 40 elementary-age students participated in this study. Only 27 families completed the post- family survey. However, this study is valuable in that it represents the progress that can be actualized for students over a short period of time. Just because bleak statistics exist regarding summer slide and students living in poverty, this does not mean that such patterns must continue. There is hope for more. With continuity and consistency, efforts such as those provided during Camp Explore could continue to support students' reading skills each summer.

Timing also impacted this study. Because of the limited time-frame, there were few assessment measures that could be integrated into Camp Explore that would not take significant learning time away from the camp experiences. Thus, running records and the McKenna survey were selected as primary measures for the students. With a longer timeframe available to researchers and students, more robust assessment tools could be integrated into camp time without sacrificing limited learning time.

\section{Reflection}

Educator Preparation Programs and P-12 schools both benefit from thoughtful collaboration; theory and practice marry so well in the field and provide optimal training experience for teacher candidates. We sought to develop an EPP-P12-Family partnership that would benefit all participantsteacher candidates, P-12 students, and student families. Our efforts resulted in multifaceted growth. Students experienced growth in reading skills and reported enjoyment. Families indicated that the literacy camp provided positive value. Current teachers and candidates were able to learn research-based strategies for reading instruction, and they were able to practice using the learned strategies in authentic ways during the summer literacy camp. The efforts of planning the partnership based on mutual need resulted in literacy success for students. Much work goes into creating successful partnerships; however, the dedicated efforts can allow for lasting relationships of support in addition to met needs. When we work together to support student literacy instead of in silos, growth happens for all involved: the EPP, the school, the students. The only summer slide remembered is one encountered on a field trip.

\section{REFERENCES}

Alexander, K. L., Entwisle, D., \& Olson, L. (2007). Lasting consequences of the summer learning gap. American Sociological Review, 72, 167-180.

Allington, R.L., \& McGill-Franzen, A. (2003). The impact of summer loss on the reading achievement gap. Phi Delta Kappan, 85, 68-75.

Bishop, R.S. (1990). Mirrors, windows, and sliding glass doors. Perspectives, 6(3), ix-xi.

Braunger, J., \& Lewis, J. (2006). Building a knowledge base in reading. Newark, DE \& Urbana, IL: International Reading Association \& the National Council of Teachers of English.

Bronfenbrenner, U. (1992). Ecological systems theory. In R. Vasta (Ed.), Six theories of child development: Revised formulations and current issues (pp. 187-249). London, England: Jessica Kingsley Publishers.

Calkins, L. (2001). The art of teaching reading. New York: Pearson.

Clay, M. (1993). Reading Recovery: A Guidebook for teachers in training. NH: Heinemann. 
Clay, M. (2001). Change over Time in Children's Literacy Development. NH: Heinemann.

Clay, M. (2000/2006). Running Records for Classroom Teachers. NH: Heinemann.

Darling-Hammond, L. (2006). Constructing $21^{\text {st }}$ century teacher education. Journal of Teacher Education, 57, 300-314.

Dee, T. (2004). The race connection. Education Next, 4, 53-59.

Dee, T. (2005). A teacher like me: Does race, ethnicity, or gender matter? The American Economic Review, 95, 158-165.

Dressman, M., \& Webster, J. (2001). Retracing Rosenblatt: A textual archaeology. Curriculum and Instruction, 36, $1-36$.

Fountas, I., \& Pinnell, G. (1996). Guided reading: Good first teaching for all children. Portsmouth, NH: Heinemann.

Pinnell, G. S., \& Fountas, I.C. (2008) The Continuum of Literacy Learning, K-8: Behaviors and Understandings to Notice, Teach, and Support. NH: Heinemann

Gambrell, L. (1996). Creating classroom cultures that increase reading motivation. The Reading Teacher, 50, 14-25.

Gambrell, L. (2011). Seven rules of engagement: What's most important to know about motivation to read. The Reading Teacher, 65, 172-178.

Garrison, J. (2014). Nashville public school students now 20\% Latino. The Tennessean. Retrieved from: https://www.tennessean.com/story/news/education/2014/09/21/nashville-public-school-students-nowlatino/16031051

Grossman, P., Hammerness, K., \& McDonald, M. (2009). Redefining teaching, re-imagining teacher education. Teachers and Teaching, 15, 273-289. doi. org/10.1080/13540600902875340

Heyns, S. (1978). Summer Learning and the Effects of Schooling. New York: Academic Press.

Jacobs, A., \& Hearne, B. (2016). "IncluCivics Report: Metro Nashville Public Schools." Metro Human Relations Commission: Metro Government of Nashville and Davidson County, TN. Retrieved from: http://www.nashville.gov/Human-Relations-Commission/IncluCivics. aspx

Johnson, P. (2000). Building Effective Programs for Summer Learning. U.S. Department of Education. Retrieved from: http://www.ed.gov/americareads/sum_build.doc

Jones, M., Hobbs, L., Kenny, J., Campbell, C., Chittleborough, G., Gilbert, A., Herbert, S., \& Redman, C. (2016). Successful university-school partnerships: An interpretive framework to inform partnership practice. Teaching and Teacher Education, 60, 108-120. doi: 10.1016/j. tate.2016.08.006

Korthagen, F., Kessels, J., Koster, B., Lagerwerf, B., \& Wubbels, T. (2001). Linking practice and theory: The pedagogy of realistic teacher education. London: Lawrence Elbaum Associates.

Lawshe, C. H. (1975). A quantitative approach to content validity. Personnel Psychology, 28, 563-575.
McCombs, J. S., Augustine, C. H., Schwartz, H. L., Bodilly, S. J., McInnis, B., Lichter, D. S., \& Cross, A. B. (2011). Making summer count: How summer programs can boost students'learning. Santa Monica, CA: RAND. Retrieved from www.rand.org/content/dam/rand/pubs/ monographs/2011/RAND_MG1120.pdf

McGill-Franzen, A., \& Allington, R. (2001). Lost summers: For some children, few books, and few opportunities to read. Classroom Leadership.

McGill-Franzen, A., Ward, N., \& Cahill, M. (2016). Summers: Some Are Reading, Some Are Not! It Matters. Reading Teacher, 69, 585-596.

McKenna, M., \& Kear, D. (1990). Measuring attitude toward reading: A new tool for teachers. The Reading Teacher, 43, 626-639.

Nell, V. (1988). The psychology of reading for pleasure: Needs and gratifications. Reading Research Quarterly, 23, 6-50.

Paquette, D. (2016). The days of stay-at-home moms are 'long gone,' data show. The Washington Post. Retrieved from http://www.chicagotribune.com/business/ct-stayat-home-moms-study-20161222-story.html

Probst, G. (2002). Managing Knowledge, Building Blocks for Success. Wiley. West Sussex, England.

Roberts, T. A. (2008). Home storybook reading in primary or second language with preschool children: Evidence of equal effectiveness for second-language vocabulary acquisition. Reading Research Quarterly, 43, 103-130.

Roman, S., \& Fiore, C. (2010). Do public library summer reading programs close the achievement gap? Children and Libraries, (Winter), 27-31.

Rosenblatt, L M. (1978). The reader, the text, the poem: The transactional theory of the literary work. Carbondale: Southern Illinois University Press.

Scott, J. \& Scott, B. (2015). They "really" don't speak English: Helping preservice teachers experience cultural and linguistic diversity. AILACTE Journal, 12(1) 17-34.

Serravallo, J. (2015). The Reading Strategies Book. Portsmouth, NH: Heinemann.

Shockley, B., Michalove, B., Allen, J. (1995). Engaging families: Connecting home and school literacy communities. Portsmouth, NH: Heinemann.

Smith, L. (2012). Slowing the summer slide. Educational Leadership, 69, 60-63. Retrieved from: shorturl.at/ kszC9

Spaulding, C. (1992). The motivation to read and write. In J. W. Irwin \& M. A. Doyle (Eds.), Reading/writing connections: Learning from research. (pp. 177-201). Newark, DE: International Reading Association.

Suitts, S. (2015). A new majority research bulletin: Low-income students now a majority in the nation's public schools. Atlanta, GA: Southern Education Foundation.

Vasquez, V., Tate, S., \& Harste, J. (2013). Negotiating critical literacies with teachers: Theoretical foundations and pedagogical resources for pre-service and in-service contexts. New York, NY: Routledge.

Vygotsky, L. (1978). Interaction between learning and development. In Gauvain \& Cole (Eds.). Readings on the 
Development of Children. New York: Scientific American Books. Pp. 34-40.

Wiley, T. G. \& de Klerk, G. (2010). Common myths and stereotypes regarding literacy and language diversity in the multilingual United States. In M. Farr, L. Seloni, \& J. Song (Eds.), Ethnolinguistic diversity and education: Language, literacy, and culture (pp. 23-43). New York, NY: Routledge.
Wilkins, C., Gersten, R., Decker, L., Grunden, L., Brasiel, S., Brunmert, K., \& Jayanthi, M. (2012). Does a summer reading program based on Lexiles affect reading comprehension? USDOE. Retrieved from: http://files.eric. ed.gov/fulltext/ED530029.pdf

Zirkel, S. (2002). Is there a place for me? Role models and academic identity among white students and students of color. Teachers College Record, 104, 357-376.

\section{APPENDIX}

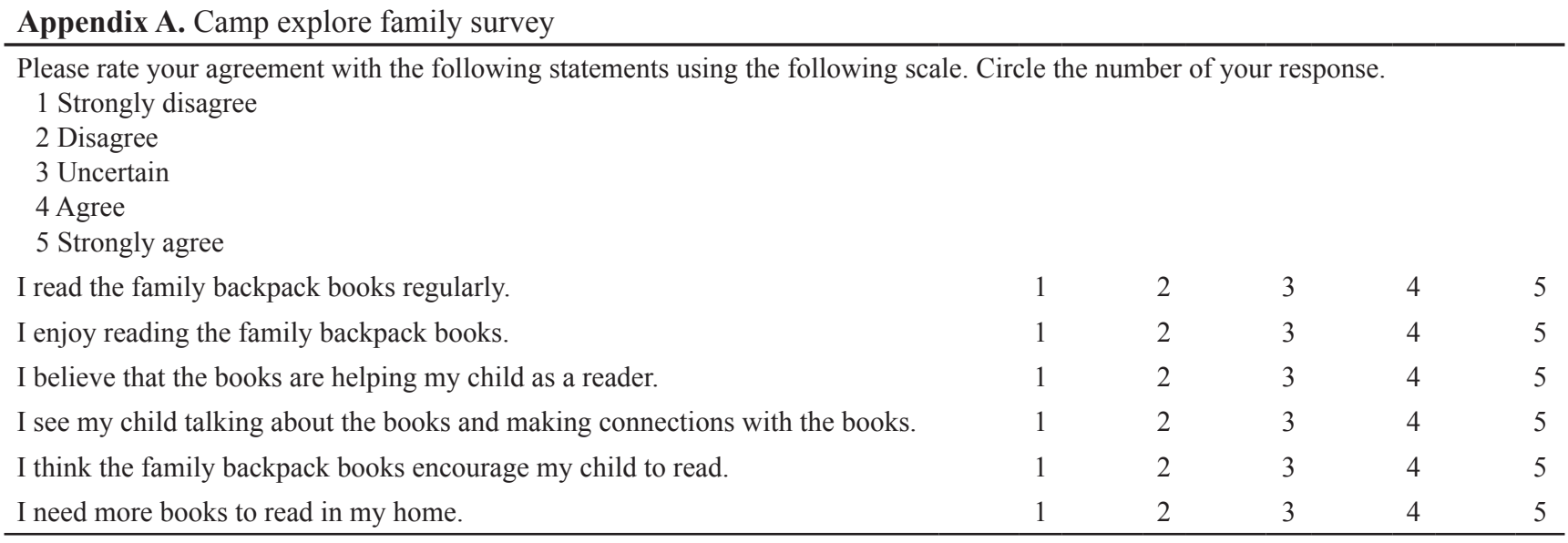

